\title{
Tindak Tutur Direktif dan Maknanya pada Komunikasi Masyarakat Betawi di Kampung Selang Cau Kecamatan Cibitung dalam Kajian Hermeneutik
}

\author{
Dwi Wahyu Ningsih" \\ Universitas Indraprasta PGRI \\ Jalan Nangka No. 58 C/TB. Simatupang, Tanjung Barat, Jakarta Selatan 12530 \\ E. Zaenal Arifin ${ }^{2)}$ \\ Universitas Indraprasta PGRI \\ Jalan Nangka No. 58 C/TB. Simatupang, Tanjung Barat, Jakarta Selatan 12530 \\ Masrin $^{3)}$ \\ Universitas Indraprasta PGRI \\ Jalan Nangka Raya No. 58 C, RT 5/RW 5, Tanjung Barat, Kec. Jagakarsa Jakarta \\ Selatan 12530
}

dwiwahyu13.dn@gmail.com ${ }^{1)}$,zaenalarifin_48@yahoo.com ${ }^{2)}$

\begin{abstract}
The purpose of this study was to see the Directional Actions and Its Meaning in Betawi Community Communication in Selang Cau Village, Cibitung District in Hermeneutic Studies. In this study, researchers used the library method, which means that researchers look for data materials or data sources related to the researcher's activities through relevant books as a theoretical basis. The research method used to analyze this research with a descriptive and qualitative objective approach that describes the material description in the Directional Speech Actions and Its Meaning in Betawi Community Communication in Kampung Selang Cau, Cibitung District in Hermeneutic Studies. This study has a work step to describe in detail the forms of directive speech in Betawi language in community communication in Selang Cau village. The more dominant use of speech acts, there were 52 directive question aspects with $44.07 \%$, the two directive aspects suggested 19 findings with 16.10\%, the three aspects of the prohibition directive were 17 findings with $14.41 \%$, the four directive aspects asked as many as 14 findings with $11.86 \%$, the five aspects of the command were 11 findings with $9.32 \%$, and finally the directive aspect gave as many as 5 findings with 16.10\%. Thus, the authors conclude that the questioning aspect of the Betawi community communication in Selang Cau village is more dominant than the other elements.
\end{abstract}

Keywords: directive speech, meaning, hermeneutic

\begin{abstract}
Abstrak
Tujuan penelitian ini untuk mengetahui Tindak Tutur Direktif dan Maknanya Pada Komunikasi Masyarakat Betawi di Kampung Selang Cau Kecamatan Cibitung dalam Kajian Hermeneutik. Dalam penelitian ini peneliti menggunakan metode pustaka yang berarti peneliti mencari bahan data atau sumber data yang berhubungan dengan kegiatan peneliti ini melalui buku-buku yang relevan sebagai landasan teori. Metode penelitian yang digunakan untuk menganalisis penelitian ini dengan menggunakan pendekatan objektif deskriptif dan kualitatif yang mendeskripsikan gambaran unsur dalam Tindak Tutur Direktif dan Maknanya Pada Komunikasi Masyarakat Betawi di Kampung Selang Cau Kecamatan Cibitung dalam Kajian Hermeneutik. Penelitian ini memiliki langkah kerja untuk mendeskripsikan secara terperinci bentuk-bentuk tidak tutur direktif pada
\end{abstract}

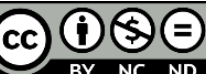

Creative Commons Attribution-NonCommercial-NoDerivatives 4.0 International License 
bahasa betawi pada komunikasi masyarakat di kampung Selang Cau. penggunaan tindak tutur direktif lebih dominan terdapat aspek direktif pertanyaan sebanyak 52 temuan dengan 44,07\%, kedua aspek direktif menasehatkan sebanyak 19 temuan dengan 16,10\%, ketiga aspek direktif larangan sebanyak 17 temuan dengan 14,41\%, keempat aspek direktif meminta sebanyak 14 temuan dengan $11,86 \%$, kelima aspek perintah sebanyak 11 temuan dengan 9,32\%, dan terakhir aspek direktif memberikan wewenang sebanyak 5 temuan dengan 16,10\%. Dengan demikian, penulis menyimpulkan bahwa aspek tindak pertanyaan pada komunikasi masyarakat betawi di kampung Selang Cau lebih dominan dibanding dengan unsur lainnya.

Kata kunci: Tindak Tutur Direktif, Makna, Hermeneutik

\section{PENDAHULUAN}

Indonesia memiliki aneka ragam budaya serta bahasa yang sangat banyak. Hal ini yang menarik untuk diteliti lebih dalam agar keanekaragamanan budaya dan bahasa tetap terjaga kelestariannya. Eksistensi bahasa dalam tataran linguistik khususnya pada bahasa daerah sudah sangat jarang digunakan pada masyarakat penuturnya. Salah satu contohnya adalah Bahasa Betawi. Bahasa Betawi merupakan salah satu ragam bahasa daerah yang digunakan sebagai bahasa komunikasi sehari-hari mayoritas masyarakat penuturnya penduduk sekitar wilayah DKI Jakarta.

Masyarakat adalah kumpulan dari orang banyak yang berbeda-beda, tetapi menyatu dalam suatu lingkup dan tata cara tertentu. Masyarakat memiliki konteks yang luas. Masyarakat pada dasarnya sangat umum dipahami dengan warga atau anggota selingkung di suatu wilayah tertentu. Betawi adalah suku yang berasal dari hasil kawin-mawin antaretnis dan bangsa pada masa lalu. Secara biologis mereka yang mengaku sebagai orang betawi adalah keturunan kaum berdarah campuran aneka suku dan bangsa yang didatangkan oleh Belanda ke Batavia. Kelompok etnis ini lahir dari perpaduan sebagai kelompok etnis lainnya yang sudah lebih dulu hidup di Jakarta seperti orang Sunda, Jawa, Bali, Bugis, Makassar, Madura, dan sebagainya.

Masyarakat Betawi dapat dikatakan sebagai kelompok atau kumpulan orang yang berada dalam suatu wilayah tertentu dengan menggunakan dialek bahasa yang sama yaitu bahasa Betawi. Masyarakat penutur bahasa Betawi dibagi menjadi dua yaitu Betawi pinggiran dan Betawi tengah. Betawi pinggiran termasuk dalam daerah Cikarang, Cibitung, Tambun, Bekasi, dan sekitar, sedangkan yang termasuk daerah Betawi tengah yaitu sekitar wilayah DKI Jakarta. Dialek Betawi pusat atau tengah seringkali dianggap sebagai dialek Betawi sejati, karena berasal dari tempat bermulanya kota Jakarta. Sebab yang membedakan dialek tengah dan dialek pinggiran diantaranya adalah dialek yang berakhiran /e/ pada gue dan /a/ pada gua yang biasanya digunakan dalam bahasa keseharian para penuturnya.

Bahasa sebagai alat komunikasi yang bersifat arbitrer menunjukkan bahwa bahasa tersebut memiliki perkembangan yang luas. Bahasa dalam kehidupan sehari-hari sangat berperan aktif karena memiliki fungsi yang sangat penting dalam kehidupan manusia. Bahasa juga dapat dikatakan sebagai identitas diri dari orang atau penutur bahasa tersebut. Bahasa di lihat dari fungsinya adalah alat komunikasi. Pemahaman seperti itu tidak salah dan tidak juga benar, tetapi hanya 
dilihat dari fungsinya saja. Hal itu bisa terjadi karena kurangnya pemahaman lebih mengenai bahasa. Bahasa sebagai sistem lambang bunyi yang digunakan oleh para anggota kelompok sosial untuk bekerjasama dan berkomunikasi. Hanya manusia yang menggunakan bahasa untuk menyampaikan tujuan dan maksud kepada seseorang.

Bahasa dalam bentuk tuturan yang dihasilkan oleh manusia dapat diekspresikan melalui bentuk lisan maupun tulisan. Suatu komunikasi dalam sebuah percakapan dikatakan berjalan dengan baik apabila tidak terjadi salah penafsiran oleh mitra tutur (Rahmawati, 2021). Dalam media lisan, pihak yang melakukan tindak tutur adalah penutur (pembicara) dan mitra tuturnya (penyimak). Dalam media tulis, tuturan disampaikan oleh penulis kepada mitra tuturnya yaitu pembaca. Seorang penutur dapat mengekspresikan tuturannya baik lisan maupun tulisan dengan memanfaatkan media lisan maupun media tulis.

Menurut Chaer dan Agustina (2004:50), tindak tutur merupakan gejala individual, bersifat psikologis, dan keberlangsungannya ditentukan oleh kemampuan bahasa si penutur dalam menghadapi situasi tertentu. Tindak tutur sebagai wujud peristiwa komunikasi bukanlah peristiwa yang terjadi dengan sendirinya melainkan mempunyai fungsi, mengandung maksud dan tujuan tertentu serta dapat menimbulkan pengaruh atau akibat pada mitra tutur. Dalam setiap tindak tutur, penutur menuturkan kalimat yang unik karena penutur berusaha menyesuaikan ujaran dengan konteksnya. Dengan demikian, teori tindak tutur lebih cenderung meneliti tentang makna kalimat bukan teori yang berusaha menganalisis struktur kalimat. Peneliti tindak tutur biasanya diterapkan pada penelitian yang objeknya karya ilmiah, tetapi tindak tutur juga bisa diterapkan pada penelitian yang objeknya penelitiannya adalah masyarakat atau penuturnya.

Tindak tutur lebih dilihat pada makna atau arti tindakan dalam tuturannya. Hymes (dalam Ibrahim, 1994:268) menyatakan bahwa tindak tutur merupakan level paling sederhana, tetapi menyulitkan. Tindak tutur dapat dibedakan menjadi beberapa, yaitu tindak tutur repsentatif adalah jenis bentuk tuturan yang berfungsi menjelaskan apa dan bagaimana sesuatu itu adanya, komisif adalah tindak tutur yang berfungsi mendorong pembicara melakukan sesuatu, ekspresif adalah tindak tutur yang menyangkut perasaan dan sikap, direktif adalah tindak tutur yang berfungsi untuk memantapkan dan membedakan sesuatu tindak tutur yang lain untuk tindak tutur sebelumnya.

Austin (dalam Nadar, 2009:11) yang mengatakan bahwa pada dasarnya saat seseorang melakukan sesuatu, dia juga melakukan sesuatu. Chaer dan Agustina (2004:16) menyatakan bahwa tindak tutur merupakan gejala individual, bersifat psikologis dan keberlangsungannya ditentukan oleh kemampuan bahasa si penutur dalam menghadapi situasi tertentu. Tarigan (1990:36) menyatakan bahwa berkaitan dengan tindak tutur maka setiap ujaran atau ucapan tertentu mengandung maksud dan tujuan tertentu pula. Dengan kata lain, kedua belah pihak, yaitu penutur dan lawan tutur terlibat dalam suatu tujuan kegiatan yang berorientasi pada tujuan tertentu

Penulis membahas tentang tindak tutur direktif (impositif) karena tindak tutur direktif ini adanya suatu makna tindakan yang dilakukan oleh seorang penutur yang disampaikan oleh penutur. Tindak tutur direktif merupakan bagian 
dari tindak tutur ilokusi yang bermaksud memberikan efek melalui tindakan atau respons dari lawan tutur. Tindak tutur direktif termasuk tuturan yang mengaharapkan tanggapan berupa tindakan dari lawan tutur. Tuturan berupa kalimat, kalimat yang diucapkan penutur mengandung tujuan yang berbeda-beda, antara lain: memerintah, meminta, memohon, mengajak, melarang, dan menyarankan.

Penelitian lain dilakukan oleh Pusparita, dkk. (2020) yaitu analisis cerpen pilihan Kompas 2017 "Kelas Bercerita" dapat disimpulkan sebagai berikut (1) Tindak tutur direktif yang paling sering digunakan adalah tindak tutur direktif pertanyaan, permintaan, perintah, menyetujui, nasihat, dan larangan. (2) Fungsi tindak tutur direktif yang paling sering digunakan dalam adalah fungsi tindak tutur menyenangkan, bekerja sama, kompetitif, dan bertentangan.

Untuk memahami tindak tutur direktif diperlukan pendekatan makna. Pendekatan ini menganggap bahwa memiliki keterkaitan dengan tindak tutur direktif dalam bahasa betawi. Karena untuk memahami bahasa betawi itu sendiri, penutur dan lawan tutur perlu adanya menyatukan persepsi dari makna bahasa itu sendiri. Agar terjalin komunikasi yang baik antara penutur dan lawan tutur. Ada pun teori yang digunakan dalam penelitian ini adalah teori hermeneutika.

\section{METODE}

Pendekatan yang digunakan dalam penelitian ini adalah pendekatan menggunakan metode penelitian kajian kualitatif. Menurut Moleong (2000) kajian kualitatif pada dasarnya dilakukan untuk menyusun teori bukan menguji teori. Atau dengan kata lain, kajian kualitatif ini untuk menemukan pengetahuan baru atau merumuskan teori baru berdasarkan data yang dikumpulkan. Kajian kualitatif ini juga bersifat menjelaskan suatu masalah, yakni masalah yang diteliti. Kajian dimulai dengan merumuskan masalah, merumuskan fokus kajian, atau mengajukan pertanyaan-pertanyaan kajian, dilanjutkan dengan pengumpulan data oleh peneliti sendiri sebagai instrumennya.

\section{HASIL DAN PEMBAHASAN}

\section{Hasil}

Data penelitian ini berupa tindak ujar atau tindak tutur pada komunikasi masyarakat Betawi di kampung Selang Cau kecamatan Cibitung. Ujaran atau tindak tutur dalam percakapan sehari-hari tersebut dianalisis berdasarkan penggunaan tindak tutur direktif berserta maknanya yang mencakup (1) Memintaan (requestives), (2) Pertanyaan (requestion), (3) Perintah (requirements), (4) Larangan (prohibitives), (5) Memberi wewenang (permissives), (6) Menasehatkan (advisories). Penulis menganalisis 190 dialog dalam komunikasi percakapan sehari-hari atau tindak tutur masyarakat Betawi di kampung Selang Cau kecamatan Cibitung. Penulis mengambil data berupa percakapan sehari-hari selama 3 hari dalam tiga pekan dengan masing-masing 
durasi 30 menit. Penelitian di lakukan dengan teknik rekam dan teknik catat yang di peroleh dari percakapan/dialog sehari-hari masyarakat Betawi di kampung Selang Cau Kecamatan Cibitung. Berdasarkan aspek temuan di atas aspek tindak tutur direktif terlihat dalam tabel persentase sebagai berikut:

Tabel 1. Hasil Temuan Tindak Tutur Direktif

\begin{tabular}{cll}
\hline No & Ukuran Deskriptif & Persentase \\
\hline 1 & Meminta & $11,86 \%$ \\
2 & Pertanyaan & $44,07 \%$ \\
3 & Perintah & $9,32 \%$ \\
4 & Larangan & $14,41 \%$ \\
5 & Memberikan Wewenang & $4,32 \%$ \\
6 & Menasehatkan & $16,10 \%$ \\
\hline
\end{tabular}

\section{Pembahasan}

Tindak tutur direktif adalah merupakan mengekspresikan maksud penutur sehingga ujaran atau sikap yang diekspresikan dijadikan sebagai alasan untuk bertindak oleh mitra tutur. Uraian tindak tutur direktif meminta, pertanyaan, perintah, larangan, memberi wewenang, dan menasehatkan, sedangkan makna adalah arti kata atau makna bahasa dari tuturan atau komunikasi masyarakat Betawi di Kampung Selang Cau. Karena dalam kajian hermeneutik sebenarnya sebuah paradigma yang berusaha menafsirkan teks atau dasar logika linguistik. Logika linguistik akan membuat penjelasan teks sastra dan pemahaman makna dengan menggunakan "makna kata" dan selanjutnya "makna bahasa".

Penulis akan menafsiran dan menguraikan penelitian tindak tutur direktif dan maknanya pada komunikasi masyarakat Betawi di Kampung Selang Cau Kecamatan Cibitung sebagai kajian Hermeneutik sebagai berikut:

Pertama tindak tutur direktif dengan klasifikasi "meminta" yaitu:

1. Gua ge belon ngiat, ongkoh gua ge baru nyampe pisan, ga lama eh lu dateng. Ama dia ge onoh minta seduhinnya, itu dia temennya sii soper yang jagain ini juga (temuan no 4).

Analisis: percakapan di atas mengandung tindak tutur direktif meminta karena terdapat kalimat penutur meminta untuk menyeduhkan kopi.

2. Dulu ngapah key, tuman bangat lu ah kalo orang tua kongko ge ah ada bae yak, sono ama Elsa noh balik gih ngaji sonoh (temuan no 50).

Analisis: percakapan di atas mengandung tindak tutur direktif meminta karena terdapat kalimat penutur meminta bersabar sebentar karean ibunya masih ngobrol.

Kedua tindak tutur direktif dengan klasifikasi "pertanyaan” yaitu:

1. Ilok? (temuan no 2).

Analisis: percakapan di atas mengandung tindak tutur direktif pertanyaan karena terdapat kalimat penutur bertanya keheranan.

2. Lah emang ngider sayur wayah ginih? (temuan no 42). 
Analisis: percakapan di atas mengandung tindak tutur direktif pertanyaan karena terdapat kalimat penutur bertanya tentang tukang sayur yang masih berkeliling.

Ketiga tindak tutur direktif dengan klasifikasi "perintah" yaitu:

1. Orangnya ora ngirim, pere katanya tadi wa gua. Yang laen ge atuh pan banyak itu. Ati noh ati, biasanya ge lu demen ama ati (temuan no11).

Analisis: percakapan di atas mengandung tindak tutur direktif perintah karena terdapat kalimat penutur memerintahkan untuk memilih menu makanan yang lain.

2. Dulu ngapah key, tuman bangat lu ah kalo orang tua kongko ge ah ada bae yak, sono ama Elsa noh balik gih ngaji sonoh (temuan no 50).

Analisis: percakapan di atas mengandung tindak tutur direktif perintah karena terdapat kalimat penutur memerintahkan untuk pulang dan pergi mengaji.

Keempat tindak tutur direktif dengan klasifikasi "larangan" yaitu:

1. Lah lu jadi gala-gala ora enak, udah kaya ama siapa bee lu A. etd atuh ge gala dua-duanya begitu. Orang mah salah satu ge A. lu pilih yang terbaik sapah di antara dua itu. Jangan semua anak wadon orang lu PHP-in sian A (temuan no 24).

Analisis: percakapan di atas mengandung tindak tutur direktif larangan karena terdapat kalimat penutur larangan untuk jangan memberikan harapan palsu pada wanita.

2. Iya biar kata ora berani ora pinter go orang mah adepin dulu tuh pak rete, jangan emosi bae maju bee dulu entar mah pagimanah ge nyautinnya (temuan no 58).

Analisis: percakapan di atas mengandung tindak tutur direktif larangan karena terdapat kalimat penutur melarang untuk jangan mendahulukan emosinya.

Kelima tindak tutur direktif dengan klasifikasi "memberi wewenang” yaitu:

1. Iya emang gua ge sempet kepikiran begitu sii nong. Ga kudu hajatan lagi emang. Paling besan doang udah. Emak gua mah udah ngerestuin bae si mao ama yang mana ge, asal gua nya bener jangan maen-maen lagih (temuan no 34).

Analisis: percakapan di atas mengandung tindak tutur direktif memberikan wewenang karena terdapat kalimat penutur memberikan izin atau restu dengan syarat sudah tidak main-main lagi.

2. Iya udah kalo begitu mah entar urusan kue mah Nde dah ngantur gimana-gimananya apan saya mah kaga ngarti (temuan no 76).

Analisis: percakapan di atas mengandung tindak tutur direktif memberikan wewenang karena terdapat kalimat penutur memberikan izin untuk mengatur semua urusan kue. 
Keenam tindak tutur direktif dengan klasifikasi "menasehatkan" yaitu:

1. Hmmm, orang kata gua seja bangat dewekan kemari mao makan nasi bakar. Gua lagi pengen tumbenan ini. Eh takanu ora ada. Orang mah nih lu nyari selingan tempat lain kalu yang hatu ora ngirim yang hatu ada kon, begitu wan (temuan no 15).

Analisis: percakapan di atas mengandung tindak tutur direktif menasetkan karena terdapat kalimat penutur memberikan saran untuk mencari supplier lain sebagai pemasok dagangannya.

2. iyak bener ya A. usaha ada ampe dua biji lagi. Umen kalo kata gua mah lu nyari yang rada naungin keadaan kita gitu (temuan no 18).

Analisis: percakapan di atas mengandung tindak tutur direktif menasetkan karena terdapat kalimat penutur memberikan nasehat untuk mencari pasangan yang bisa menerima keadaannya.

\section{SIMPULAN}

Berdasarkan penelitian yang telah dilakukan mengenai tindak tutur direktif penulis memperoleh 118 temuan dari dialog/percakapan sehari-hari masyarakat Betawi di Kampung Selang Cau. Aspek tindak tutur direktif penulis dapat menyimpulkan bahwa penggunaan tindak tutur direktif lebih dominan terdapat aspek direktif pertanyaan sebanyak 52 temuan dengan 44,07\%. Berdasarkan penelitian makna yang di ambil dari kajian hermeneutik, penulis memberikan makna dari setiap temuan penelitiannya. Penulis memaknai atau mengartikan tindak ujar dengan makna bahasa seutuhnya dalam komunikasi masyarakat betawi.

\section{DAFTAR PUSTAKA}

Chaer, A., \& Agustina, L. (2004). Sosiolinguistik. Jakarta: Rineka Cipta. Ibrahim, A. S. (1994). Kajian tindak tutur. Surabaya: Usaha Nasional.

Moleong, L. J. (2000). Metodologi penelitian kualitatif. Bandung: PT Remaja Rosda Karya.

Nadar, F. X. (2009). Pragmatik dan penelitian pragmatik. Yogyakarta: Graha Ilmu.

Pusparita, I., \& Sumadyo, B. (2020). tindak tutur direktif dan fungsinya dalam Kumpulan Cerpen Pilihan Kompas 2017 "Kelas Bercerita". Diskursus: Jurnal Pendidikan Bahasa Indonesia, 3(01), 35-43.

Rahmawati, N. (2021). Pelanggaran prinsip kerja sama dan prinsip kesantunan berbahasa percakapan dalam acara "Mata Najwa". Diskursus: Jurnal Pendidikan Bahasa Indonesia, 4(1), 46-55.

Tarigan, H. G. (1990). Pengajaran kompetensi bahasa. Edisi Revisi. Bandung: Angkasa. 